\title{
Adolescents' proxy reports on obesity-related parenting practices: Factorial validity and reliability across four behavioral domains
}

\section{Gabriel L Fuligni}

Cornell University

Christopher J Gonzalez

Weill Cornell Medicine

Roger Figueroa ( $\nabla$ rf453@cornell.edu )

Cornell University

\section{Research Article}

Keywords: obesity-related parenting, parent-adolescent dyads, confirmatory factor analysis, actor-partner interdependence

Posted Date: August 18th, 2021

DOI: https://doi.org/10.21203/rs.3.rs-789279/v1

License: @ (i) This work is licensed under a Creative Commons Attribution 4.0 International License. Read Full License 


\section{Abstract \\ Background}

Energy-balance behaviors are precursors to obesity shaped by the practices or strategies that many parents implement. Although key stakeholders to their families, adolescents are rarely considered to report on these obesity-related parenting practices. The aim of this study is to assess the factorial and predictive validity of adolescents' proxy-report of parents' obesity-related parenting across four behavioral domains.

\section{Methods}

This study used data from the Family Life, Activity, Sun, Health, and Eating (FLASHE) study. This study tests whether adolescents' proxy reports about their parents' obesity-related parenting are significantly associated with parents' responses on their own obesity-related parenting, as well as whether these reports are significantly associated to parent-adolescent energy-balance behaviors. Factorial validity was assessed using linear regression and Confirmatory Factor Analysis (CFA), whereas predictive validity was assessed using Actor-Partner Interdependence Modeling (APIM).

\section{Results}

Regression results indicated that adolescents' proxy report is significantly associated with parents' report of their own parenting in all four domains $(\beta=.59-.71 ; p<0.05)$. CFA results indicated a final factor structure that loaded significantly onto hypothesized obesity-related parenting domains $(\beta>.30)$ in both adolescents and parents. APIM results indicated that both parent- $(\beta=.32 ; p<0.05)$ and adolescent $(\beta$ $=.21 ; p<0.05)$ reported obesity parenting for fruit and vegetable consumption were associated with their own fruit and vegetable intake. In addition, adolescent-reported physical activity parenting was significantly associated with adolescent physical activity $(\beta=0.23 ; p<0.05)$. Regarding partner effects, only parent-reported parenting for fruit and vegetable consumption were significantly associated with adolescent intake of fruit and vegetables $(\beta=0.15, p<0.05)$ and adolescent-reported physical activity parenting was significantly associated with parental physical activity $(\beta=0.16, p<0.05)$. Neither adolescent nor parent reported parenting were significantly associated with screen time or junk food intake outcomes. Each final obesity-related parenting scale had good internal consistency $(a=.74-85)$.

\section{Conclusions}

We found that adolescent- and parent-reported obesity-related parenting were significantly associated, while adolescent-reported parenting were more influential of fruit and vegetable intake and physical 
activity than parent-reported parenting. These findings suggest that adolescent proxy reports may be a valid source of information on obesity-related parenting.

\section{Background}

Over twenty percent of U.S. adolescents, defined here as 12- to 19-year-olds, are overweight or obese, and rates continue to increase nationwide [1]. Such alarming prevalence are consistent with global obesity trends among adolescents, driven by increases in calorie-rich and energy-dense foods and increased engagement in sedentary behaviors [2]. Obesity puts adolescents at risk for a variety of adverse outcomes, including type 2 diabetes, metabolic syndrome, and cardiovascular disease [3, 4]. Adolescents with obesity are also more likely to experience social stigma and psychological comorbidities, including depression, emotional and behavioral disorders, and low self-esteem [5]. Obesity during adolescence greatly increases the risk of obesity in adulthood, due in part to impacting self-regulatory processes in this key period of brain development and leads to a greater risk of cardiovascular disease and several forms of cancer $[3,6,7]$.

A variety of socio-ecological determinants can contribute to the development of obesity, including energy balance behaviors (i.e., diet and physical activity), psychosocial factors such as abuse, depression, and anxiety, and environmental factors, such as neighborhood walkability, fast food density, and access to healthy food options [2, 8-12]. Put simply, weight gain is caused by energy intake exceeding energy expenditure [13]. Given the critical impact of adolescent obesity on health and its growing prevalence globally and nationally, research on understanding additional ways to tackle this public health problem requires prioritization. This paper focuses on the most proximal determinant of obesity, energy balance behaviors, and how they are shaped by the family context through parenting.

Being a primary agent of socialization, the family has great influence on the learning and development of behavior patterns among adolescents and is therefore an important area of study of adolescent obesity research [14]. Parents and their rearing practices have an important role in determining the energy balance behaviors of their adolescent children, both in terms of dietary intake and physical activity. Research has shown that parenting practices such as setting limitations on screen time, valuing and providing logistical support for being physically active, and parents themselves engaging in physical activity are associated with adolescents' physical activity [15-19]. Similarly, adolescents' diet is associated with parental encouragement, family eating rules, food availability at home, and parental diet $[20,21]$. These findings highlight that parenting practices may have great influence on adolescents' energy balance behaviors and indicate that investigating family influences (i.e., parenting practices) on obesity is vital to understanding and preventing obesity among adolescents.

Obesity-related parenting practices are of particular focus in the context of this study. Obesity-related parenting is defined as parenting practices associated to diet and physical activity promotion [22]. Although valid instruments for assessing obesity-related parenting practices exist, there are some notable gaps in the way parenting practices are currently measured [23] (Baranowski, 2013). In seven studies 
examining obesity-related parenting practices on adolescents' energy balance behaviors, researchers focus on physical activity or diet as study outcomes, but not both within the same study [15, 24-29]. Also, the majority of these studies account for reports from either parents or adolescents only, with the exception of one study with a sample of 104 adolescent-parent dyads. Systematic review evidence shows that out of 72 obesity-related parenting (i.e., food parenting) studies investigated, 11 included no validity evidence, most of the studies only demonstrated construct validity, only ten reported confirmatory factor analyses, and only two demonstrated criterion validity [30]. Noticeably, there is a need for more validated tools to measure obesity-related parenting behaviors.

The critical gap that this study aims to address is the use of adolescents as proxy reporters on their parents' obesity-related parenting practices. Research on parenting practices presents a host of challenges, and proxy reports (especially from the direct recipients of those rearing practices) offers a potential way to increase response rates and reduce costs and time associated with the collection of these data [23,31]. In assessing the validity of adolescent reports of obesity-related parenting, our research team expects to provide a new avenue for research on obesity influences in the family context by introducing key validated measurements that allow for more predictive power of adolescents' obesityrelated outcomes.

This study has two central aims. First, to assess the validity and reliability of measurement tool of obesity-related parenting practices, both through parent and adolescent reports. Our second aim is to test the associations between the obesity-related parenting practices and energy balance behaviors (i.e., diet and physical activity), and compare the strengths of these associations between parent and adolescent reports. We hope to reach conclusions about the validity and usefulness of adolescent proxy reports of obesity-related parenting practices that will inform future research on obesity prevention.

\section{Methods}

\section{Study Sample}

This study utilizes data collected in the National Cancer Institute's Family Life, Activity, Sun, Health, and Eating (FLASHE) study. This cross-sectional study administered a web-based survey to investigate psychosocial and environmental correlates of eating and physical activity behaviors among parents and adolescents separately. Adolescents were eligible for participation if they were between ages 12 and 17 and lived with the parent more than $50 \%$ of the time, and parents were eligible for participation if they were at least 18 years of age and lived with the adolescent more than $50 \%$ of the time, per the inclusion criteria of the FLASHE study. The sample included 1,849 parent-adolescent dyads who were recruited from across the United States via print ads, internet banner ads, random digit dialing omnibus surveys, and panelist referrals and screened for eligibility [32]. The sample was collected to reflect the US population distribution based on gender, census division, household income, household size, among others. The FLASHE study utilized two surveys, one collecting data on diet and one collecting data on 
physical activity, along with a demographic survey attached to whichever survey was completed first. Surveys were conducted between April and October of 2014 [33].

\section{Measures}

Parenting practices. The current study analyzes variables related to parenting practices in four behavioral domains: 1) fruit and vegetable intake, 2) junk food and sugar beverage intake, 3) physical activity, and 4) screen time. Parenting for fruit and vegetable intake was assessed through seven (7) items adapted from the Child Feeding Questionnaire, the Comprehensive Feeding Questionnaire, the Parental Feeding Style Questionnaire, Legitimacy of Parental Authority, with one new survey item created for this study [34-37]. Parenting for junk food and sugary drink intake was assessed through seven (7) items adapted from the same four sources as the fruit and vegetable survey items. Physical activity parenting was assessed through six (6) items adapted from the Parenting Eating and activity Scale, the Activity Support Scale, the Comprehensive Feeding Practices Questionnaire, and the Legitimacy of Parental Authority, with one new survey item created for this study [35, 36, 38, 39]. Screen time parenting was assessed through seven (7) items adapted from the same four sources as the physical activity survey items. Item response options across five-point Likert scales ranged from strongly disagree to strongly agree.

\section{Energy balance behaviors}

Energy balance behaviors (i.e., fruit, vegetable intake, sugar was taken from self-reports on adolescents' and parents' behaviors in each of these four domains representing the behaviors the parenting practices aimed to promote or prevent, i.e., daily servings of fruits and vegetables or weekly screen time. The outcome variable for fruit and vegetable intake was generated from responses on two questions asking how many times in the past 7 days the respondent consumed fruits and vegetables, respectively. Their responses to these two questions were divided by seven and added together to yield a total average daily intake of fruits and vegetables. The outcome variable for junk food and sugary beverage intake was generated similarly from weekly responses of intake of junk food and sugary beverages. The outcome variable for physical activity was generated by taking the sum of self-reported weekly minutes spent doing moderate physical activity and twice the self-reported weekly minutes spent doing vigorous physical activity. The Centers for Disease Control and Prevention recommends 150 minutes of moderateto vigorous activity for adults and 60 minutes daily for adolescents [40]. The outcome variable for screen time was generated from taking the sum of the self-reported daily time spent on a phone, TV, computer, or video game.

Demographics. Both adolescents and parents completed a demographic survey. For the adolescents, demographic variables include gender, age, race, and ethnicity, and for the parents, demographic variables include gender, age, education level, race, and ethnicity.

\section{Statistical Analysis}

Statistical analysis was conducted on STATA, version 16, between August 2020 and March 2021. Statistical significance was set at $p<.05$. Initially, univariate descriptive statistics were obtained for the 
demographic variables and the variables of all four parenting domains. Subsequently, bivariate statistics (i.e., Pearson's Correlation, OLS regression) were used to assess the relationship between parent- and adolescent-reported obesity parenting at the item and the domain level. Next, internal consistency for each parenting domain, at the individual level (parent or adolescent separately), was assessed using Cronbach's alpha [41]. Items were reverse coded where appropriate so that, for each item, a higher number indicates parenting that promotes the behavior, and a lower number indicates parenting that restricts or inhibits said behavior. Next, factorial validity was tested for each of the four obesity parenting domains, as well as measurement invariance across adolescent and parent reports using confirmatory factor analysis. For the confirmatory factor analysis models and invariance models, goodness of fit was assessed by collecting the root mean square error of approximation, standardized root mean square residual (both absolute measures of fit), and the Comparative Fit Index (incremental measure of fit). Model fit was acceptable if it met two of the following three criteria: A root mean square error of approximation less than or equal to 0.08 , a standardized root mean square residual of less than 0.10 , and a comparative fit index of greater than 0.90 [42]. Lastly, predictive validity was assessed using ActorPartner Interdependence Modeling (APIM), where adolescent and parent responses on obesity-related parenting were associated to behavioral outcomes. The APIMs were adjusted for parent sex and education level.

\section{Results}

The study sample consisted of 1,859 total adolescent-parent dyads. Of the parents, $71.60 \%$ were mothers and $25.30 \%$ were fathers. Most parents were between the ages of 35 and $44(43.56 \%)$, as well as between the ages of 45 and 59 (42.28\%). Nearly half of the parents in the study had a four-year degree or higher (46.45\%). Over a third of the parent sample identified as Non-Hispanic (NH) White, while $17.66 \%$ were $\mathrm{NH}$ Black or African American and $7.31 \%$ were Hispanic/Latino. In the adolescent sample, $45.10 \%$ were males and $45.50 \%$ were females ranging in age from 12 to 17 years old. Nearly a third of the adolescent sample were $\mathrm{NH}$ White (63.69\%), while $17.0 \%$ were NH Black or African American and $10.0 \%$ were Hispanic/Latino. The remaining demographic characteristics are summarized in Table 1. 
Table 1

Descriptive statistics of the study sample $(n=1,849)$.

\begin{tabular}{|c|c|c|}
\hline Characteristics & Parents & Adolescents \\
\hline \multicolumn{3}{|l|}{ Sex, n (\%) } \\
\hline Female & $1,325(71.6)$ & $843(45.5)$ \\
\hline Male & $468(25.3)$ & $835(45.1)$ \\
\hline \multicolumn{3}{|l|}{ Age, n (\%) } \\
\hline 12 & - & $224(13.3)$ \\
\hline 13 & - & $336(20.0)$ \\
\hline 14 & - & $280(16.7)$ \\
\hline 15 & - & $305(18.1)$ \\
\hline 16 & - & 331 (19.7) \\
\hline 17 & - & $206(12.3)$ \\
\hline $18-34$ & $202(11.3)$ & - \\
\hline $35-44$ & $781(43.6)$ & - \\
\hline $45-59$ & 758 (42.3) & - \\
\hline $60+$ & $52(2.9)$ & - \\
\hline \multicolumn{3}{|l|}{ Highest education level, n (\%) } \\
\hline Less than high school & $22(1.2)$ & - \\
\hline High school degree or Equivalent & $301(16.8)$ & - \\
\hline Some college & $634(35.5)$ & - \\
\hline Four-year degree or higher & $830(46.5)$ & - \\
\hline \multicolumn{3}{|l|}{ Race and ethnicity, n (\%) } \\
\hline Hispanic & $130(7.3)$ & $168(10.0)$ \\
\hline Non-Hispanic Black or African American & $314(17.7)$ & $283(17.0)$ \\
\hline Non-Hispanic White & $1,229(69.1)$ & $1,061(63.69)$ \\
\hline Non-Hispanic other race or ethnicity & $105(5.91)$ & $154(9.24)$ \\
\hline \multicolumn{3}{|l|}{ Energy balance behaviors (SD) } \\
\hline Fruit and vegetable intake (average servings consumed daily) & $1.76(1.31)$ & $1.48(1.22)$ \\
\hline
\end{tabular}




\section{Characteristics}

Physical activity (average weekly minutes)

Junk food and sugary drinks intake (average servings consumed daily)

Screen time (average daily hours)

Note: Due to missing data, some of these categories will not add up to the total number of survey respondents.

At the item level, adolescents' reports of obesity parenting were correlated with their parents' reports across all four domains $(r=0.31-0.58)$. Only three items within the physical activity and screen time parenting were not retained with coefficients below $0.30(r=0.27-0.29 ; \beta=0.00-0.24)$. At the domain level, adolescents' reports of obesity parenting were correlated with their parents' reports across all four domains $(r=0.57-0.62)$. In regression, adolescents' report of obesity parenting was associated with their parents' report across all four domains $\left(\beta=0.59-0.70 ; p<0.001 ; \mathrm{R}^{2}=0.32-0.37\right)$ (Table 2$)$.

Table 2

OLS regression models between adolescent- and parent-reported obesity-related parenting practices $(\mathrm{n}=$ 1,591).

\begin{tabular}{|lllll|}
\hline Parenting Domain & Alpha (SE) & Beta (SE) & T statistic $\boldsymbol{p}$ value & $\mathbf{R}^{2}$ \\
\hline Fruit and vegetable parenting & $0.99(0.09)$ & $0.70(0.02)$ & 0.01 & 0.34 \\
\hline Junk food parenting & $0.64(0.08)$ & $0.64(0.02)$ & 0.01 & 0.32 \\
\hline Physical activity parenting & $0.93(0.07)$ & $0.66(0.02)$ & 0.01 & 0.37 \\
\hline Screen time parenting & $1.03(0.07)$ & $0.59(0.02)$ & 0.01 & 0.32 \\
\hline $\begin{array}{l}\text { Note: All OLS regression models were unadjusted. Adolescent-reported parenting practices served as } \\
\text { the independent variable in all models, whereas parent-reported obesity-related parenting practices } \\
\text { served as the dependent variable. Due to missingness, the sample size at baseline was reduced in } \\
\text { these models using listwise deletion approach. }\end{array}$ \\
\hline
\end{tabular}

Results from CFA models (Table 3 ) show that obesity parenting indicators significantly loaded onto all four respective domains in adolescents and parents $(\beta=0.45-0.85 ; p<0.001 ; \mathrm{CFI}=0.93-0.99$; SRMR $=$ $0.01-0.05)$, which goodness of fit criteria. With regards to measurement invariance, CFA results only supported a single factor screen time parenting model that met metric invariance between parents and adolescents $(\Delta \mathrm{CFI}=0.05 ; \Delta \mathrm{RMSEA}=0.01 ; \Delta \mathrm{SRMR}=0.03)$. 
Table 3

CFA results for the final factor structure for each obesity-related parenting domain $(n=1,765 ; p<0.05)$.

\section{Survey Item (shown as on parent survey)}

Parents Adolescents

\section{Fruit and Vegetable Parenting}

1. I buy fruits and vegetables for my teenager.

$0.54 \quad 0.52$

2. I try to eat fruits and vegetables when my teenager is around.

$0.62 \quad 0.63$

3. I encourage my teenager to try different kinds of fruits and vegetables.

$0.67 \quad 0.62$

$\begin{array}{llll}\text { 4. My teenager and I decide how many fruits and vegetables he/she has to } & 0.64 & 0.72\end{array}$ eat.

$\begin{array}{lll}\text { 5. I have to make sure that my teenager eats enough fruits and vegetables. } & 0.51 & 0.67\end{array}$

6. I make my teenager eat fruits and vegetables.

$0.57 \quad 0.62$

$\begin{array}{llll}\text { 7. It's okay for me to make rules about how many fruits and vegetables my } & 0.52 & 0.62\end{array}$ teenager can have.

RMSEA

0.12

0.14

$\mathrm{CFI}$

0.94

0.94

SRMR

0.04

0.06

\section{Junk Food Parenting}

1. If my teenager has a bad day, I let him/her have junk food/sugary drinks to feel better.

2. I don't buy a lot of junk food or sugary drinks for my teenager.

$\begin{array}{lll}\text { 3. I try to avoid junk food or sugary drinks when my teenager is around. } & 0.32 & 0.45\end{array}$

4. My teenager and I decide together how much junk food or sugary drinks $\quad \begin{array}{lll}0.55 & 0.81\end{array}$ he/she can have.

5. I have to make sure that my teenager doesn't eat too much junk food or $\quad 0.80 \quad 0.64$ drink too many sugary drinks.

$\begin{array}{llll}\text { 6. I decide how much junk food or sugary drinks my teenager can have. } & 0.82 & 0.73\end{array}$

$\begin{array}{lll}\text { 7. It's okay for me to make rules about how much junk food or sugary } & 0.54 & 0.59\end{array}$ drinks my teenager can have.

RMSEA

$\mathrm{CFI}$

SRMR

Physical Activity Parenting

1. I have to make sure my teenager gets enough physical activity.

0.61

0.66 
Parents

0.54

0.61

2. I take my teenager places where he/she can by physically active.

3. My teenager and I decide together how much physical activity he/she has to do.

4. I make my teenager exercise or go out and play.

5. I try to be physically active when my teenager is around.

6. It's okay for me to make rules about how much time my teenager spends being physically active/playing.

RMSEA

$\mathrm{CFI}$

SRMR

\section{Screen Time Parenting}

1. If my teenager has a bad day, I let him/her have screen time to feel better.

2. My teenager and I decide together how much screen time he/she can have.

3. I take my teenager places where he/she can play video games, watch movies, etc.

4. I decide how much screen time my teenager can have.

5. I have to make sure my teenager does not have too much screen time.

6. I try to limit my own screen time when my teenager is around.

7. It's okay for me to make rules about how much screen time my teenager can have.

RMSEA

$\mathrm{CFI}$

SRMR

Due to missingness, the sample size at baseline was reduced in these models using listwise deletion approach.

Results from the APIM analyses are summarized in Table 4. The standardized parameter estimates are reported to compare models across parenting domains. Regarding actor effects, both parent- and adolescent-reported parenting practices for fruit and vegetable consumption were significantly associated with their own fruit and vegetable intake $(\beta=0.21-0.32 ; p<0.05)$. In addition, adolescentreported physical activity parenting practices were significantly associated with adolescent physical activity $(\beta=0.23 ; p<0.05)$. Regarding partner effects, only parent-reported parenting practices for fruit 
and vegetable consumption were significantly associated with adolescent intake of fruit and vegetables $(\beta=0.15, p<0.05)$ and adolescent-reported physical activity parenting practices were significantly associated with parental physical activity $(\beta=0.16, p<0.05)$. Neither adolescent nor parent reported parenting practices were significantly associated with screen time or junk food intake outcomes.

Table 4

APIM models assessing the interdependent associations between obesity-related parenting practices and energy balance behaviors among parent-adolescent dyads. $(n=1,583)$.

\begin{tabular}{|lllllllll|}
\hline \multicolumn{3}{|c}{$\begin{array}{l}\text { Vruit and } \\
\text { Vegetable }\end{array}$} \\
\hline $\begin{array}{l}\text { Dyad } \\
\text { pathway }\end{array}$ & $\begin{array}{l}\text { Actor } \\
\text { effect }\end{array}$ & $\begin{array}{l}\text { Partner } \\
\text { effect }\end{array}$ & $\begin{array}{l}\text { Actor } \\
\text { effect }\end{array}$ & $\begin{array}{l}\text { Partner } \\
\text { effect }\end{array}$ & $\begin{array}{l}\text { Actor } \\
\text { effect }\end{array}$ & $\begin{array}{l}\text { Partner } \\
\text { effect }\end{array}$ & $\begin{array}{l}\text { Actor } \\
\text { effect }\end{array}$ & $\begin{array}{l}\text { Partner } \\
\text { effect }\end{array}$ \\
\hline $\begin{array}{l}\text { Parent- } \\
\text { adolescent }\end{array}$ & 0.32 & 0.15 & - & - & - & - & - & - \\
\hline $\begin{array}{l}\text { Adolescent- } \\
\text { parent }\end{array}$ & 0.21 & - & - & - & 0.23 & 0.16 & - & - \\
\hline Note: All standardized parameter estimates presented in the table are significant at $p<0.05$. & \\
\hline
\end{tabular}

Table 5 describes internal consistency for each factor (Cronbach's a) as well as summary statistics for each item in the final factor structure across parenting domains. There was good internal consistency across parenting domains among both adolescents $(a=0.79-0.85)$ and parents $(a=0.74-0.83)$. 
Table 5

Descriptive and internal consistency statistics for obesity-related parenting domains.

Survey Item (shown as on parent survey)
Mean (SD)

Parents Adolescents

\section{Fruit and Vegetable Parenting}

1. I buy fruits and vegetables for my teenager.

4.47

$(0.76)$

$4.47(0.83)$

4.16

(0.94)

$4.09(1.05)$

2. I try to eat fruits and vegetables when my teenager is around.

4.44

$(0.74)$

3. I encourage my teenager to try different kinds of fruits and vegetables.

4. My teenager and I decide how many fruits and vegetables he/she has to eat.

3.16

(1.22)

$3.09(1.31)$

5. I have to make sure that my teenager eats enough fruits and vegetables.

3.92

(1.17)

$3.44(1.32)$

6. I make my teenager eat fruits and vegetables.

3.36

(1.27)

$4.35(0.89)$

3.85

(1.06)

7. It's okay for me to
teenager can have.

$a=$

0.78

Cronbach's alpha

(1)

\section{Junk Food Parenting}

1. If my teenager has a bad day, I let him/her have junk food/sugary drinks to feel better.

2. I don't buy a lot of junk food or sugary drinks for my teenager.

3. I try to avoid junk food or sugary drinks when my teenager is around.

4. My teenager and I decide together how much junk food or sugary drinks he/she can have.

5. I have to make sure that my teenager doesn't eat too much junk food or drink too many sugary drinks.

3.60

$(1.24)$

6. I decide how much junk food or sugary drinks my teenager can have.

7. It's okay for me to make rules about how much junk food or sugary drinks my teenager can have.

$\begin{array}{ll}a= & a=0.79 \\ 0.74 & \end{array}$




\section{Physical Activity Parenting}

1. I have to make sure my teenager gets enough physical activity.

2. I take my teenager places where he/she can by physically active.

3. My teenager and I decide together how much physical activity he/she has to do.

4. I make my teenager exercise or go out and play.

5. I try to be physically active when my teenager is around.

6. It's okay for me to make rules about how much time my teenager spends being physically active/playing.

3.72

(1.02)

Cronbach's alpha

$\begin{array}{ll}a= & a=0.79 \\ 0.80 & \end{array}$

\section{Screen Time Parenting}

1. If my teenager has a bad day, I let him/her have screen time to feel better.

2. My teenager and I decide together how much screen time he/she can have.

3. I take my teenager places where he/she can play video games, watch movies, etc.

4. I decide how much screen time my teenager can have.

5. I have to make sure my teenager does not have too much screen time.

6. I try to limit my own screen time when my teenager is around.

7. It's okay for me to make rules about how much screen time my teenager can have.

Cronbach's alpha

$\begin{array}{ll}a= & a=0.85 \\ 0.82 & \end{array}$

Note: Each item was answered on a Likert scale from 1 to 5 , with a 1 indicating strongly disagree and a 5 indicating strongly agree.

\section{Discussion}


Given the public health risks associated with obesity and the strong demonstrated influence that parents can have on their children's energy balance behaviors - one of the most proximal determinants of obesity - understanding and improving obesity-related parenting practices is warranted [13-19]. Advancing current and future obesity-prevention efforts necessitates the reduction of gaps and barriers to effective measurement of such parenting practices.

Obesity-related parenting practices must be measured more consistently and validly [30,43, 44], but researchers must also address the challenges of gathering parenting data such as cost, time intensiveness, and low response rates, particularly if populations are hardly reached $[23,31]$.

This project study aimed to assess the role of proxy reports from the recipients of obesity-related parenting practices (i.e., adolescent children) as prospective obesity parenting measurement targets. We found that adolescent responses were significantly correlated with parent responses on their obesityrelated parenting practices across parenting domains, and each construct showed strong internal consistency. Also, we found statistically significant invariance in the screen time parenting measure across groups. Lastly, actor-partner effects showed that both parent- and adolescent-reported parenting practices for fruit and vegetable consumption were associated with parent- and adolescent-reported fruit and vegetable intake (3 out of 4 pathways), and only adolescent-reported physical activity parenting practices were associated with parental physical activity and their own physical activity.

Establishing the validity of these four obesity-related parenting domains addresses a significant gap in the literature on obesity-related parenting. Systematic reviews conducted by Vaughn et al. and Davison et al. on the measurement of diet-related and physical activity-related parenting practices, respectively, demonstrated need for obesity-related parenting practices measurement tools with established validity $[30,44]$. An additional review study of physical activity parenting measurement found widespread use of non-validated tools [43]. With the validation approach taken in our study, we hope future research adopts well validated tools to measure obesity-related parenting.

Adolescents' reports on their parents' obesity-related parenting practices were also evaluated with regards to their similarity to their parents' reports on the same obesity-related parenting practices. Our findings show that they are significantly associated. This is indicative of the relative congruity between adolescent proxy-reports and parent self-reports of their obesity-related parenting practices. While the literature is limited, our validation results support prior findings that adolescent proxy reports may be a valid source of information on obesity-related parenting practices. Previous research has found child proxy reports of parents' behaviors are less accurate than self-report, but also showed that accuracy increased as children were older $[31,45,46]$. Additionally, much of this work was investigating reports on socioeconomic status, not parenting practices, and there is evidence to suggest that child proxy reports are more accurate in areas that are more salient to them [31]. Considering that obesity-related parenting practices are reasonably salient to adolescents, our findings support past research and suggest that adolescents are reliable sources of information on obesity-related parenting practices. 
In addition to the factorial validity and reliability of adolescent proxy reports, the predictive validity of adolescent- and parent-reported obesity-related parenting practices on diet and physical activity outcomes was also measured and compared. This was an important additional step because obesityrelated parenting practices are most pertinent to the public health issue of obesity in how they influence energy balance behaviors. By modeling actor-partner effects, we found that both adolescent and parent reports on fruit and vegetable parenting practices were predictive of adolescent fruit and vegetable intake, but adolescent reports yielded a higher slope coefficient at a higher significance level than parent reports. With physical activity, only adolescent reports of parenting practices predicted adolescent outcomes. Only one small study has assessed parent-practices in parent-child dyads, but it found that child reports of obesity-related parenting practices were associated with child diet and physical activity, but parent reports were not [47]. There are two major hypothesized reasons why adolescent proxy reports on parenting could be more predictive of behavioral outcomes: parent reports may be subject to social desirability bias, and the effects parenting behaviors have on adolescent behaviors likely be contingent on adolescent perceptions of them [48]. As such, our findings suggest that parent- and adolescent-reported parenting practices correlated very well, thus parent-reporter bias is unlikely to have had an impact in the study outcomes.

This finding that adolescent proxy reports could potentially be more predictive of adolescent energy balance behaviors has substantial implications for future research on obesity-related parenting practices. The primary justification for studying obesity-related parenting practices is the strong influence they may have on energy balance behaviors. Our findings suggest that adolescent-reported parenting practices are more predictive of pertinent behavioral outcomes than those that are parent-reported, and as such, might be a relatively more accurate source of parental influence, rather than simply a valid alternative proxy. Future work should be conducted to further clarify and confirm this disparity of predictivity between adolescent and parent reports and the reasons for this disparity, as well why neither adolescent nor parent reported screen time and junk food parenting practices were predictive of relevant behavioral outcomes.

There have long been issues with measurement of parenting practices, including but not limited to cost, time, response rate, and bias [23]. Adolescent proxy reports could potentially address some of these barriers [31]. In studies that are gathering data from adolescents that should be analyzed in comparison with parenting practices, the ability to gather that information from only one study subject, rather than bringing parents in would greatly lift the logistical burden of such research. Furthermore, the existence of schools and other community settings as centralized places to partner with, recruit, and follow up with adolescents may make them a study population that is feasibly approachable. In these ways and others, using adolescent proxy reports could offer an avenue that makes research on parenting practices more feasibly, and could open doors to research on otherwise hard to reach populations. These findings are also promising for future family-based obesity prevention strategies, as this indicates that adolescents could be trustworthy stakeholders in obesity prevention research and interventions. 
There are several strengths to this study. First, data was taken from a large sample that was selected to be demographically representative of the U.S. population. This allows for generalizability of the findings in this study at the population level. Furthermore, having dyadic data from parents and their adolescent children allowed for direct, ensuring that the parent-adolescent reports were on the same parenting practices. Furthermore, including four obesity-related parenting domains allowed our team to get a more complete picture of this concept and how adolescents report on them, rather than focusing in on behavioral domains independently. Another important strength of this study is the variety of validation steps that were taken to ensure the parenting practices measures included in our study were rigorously validated; this is contrasted with past studies that have often used unvalidated tools [43].

There are a few limitations to this study that are important to mention. The main outcome measures rely on self-report data, which can be vulnerable to social desirability bias, as respondents may feel they should answer to reflect what they should be doing rather than what they actually do. Past research has shown that on self-reported questionnaires, social desirability bias can lead to underreporting of eating and overreporting of physical activity $[49,50]$. Our reports on energy balance behaviors can also be subject to recall bias; past research has shown that asking for self-reports of physical activity in the past can be flawed when compared to data collection of more recent physical activity, such as in the form of a daily diary [51]. Lastly, our study did not assess gender concordance between parents and adolescents which some evidence suggests it is relevant to the influence of parenting practices $[52,53]$, which future studies should account for this contribution.

\section{Conclusion}

The goal of this study was to assess the factorial and predictive validity of adolescents' proxy-report of parents' obesity-related parenting across four behavioral domains. We found that adolescent- and parentreported obesity-related parenting practices were significantly associated, while adolescent-reported parenting practices were more influential of fruit and vegetable intake and physical activity than parentreported parenting practices. Future work should consider adolescents as key stakeholders of familybased obesity research and prevention efforts.

\section{Abbreviations}

NH: Non-Hispanic; FLASHE: Family Life, Activity, Sun, Health, and Eating.

\section{Declarations}

\section{Ethics and Consent to participate}

The ethics board at Cornell University reviewed and approved the research conducted. FLASHE data collection materials and procedures were reviewed and approved by the NCl's Special Studies Institutional Review Board (SSIRB) (iRIS No. 327123), Westat IRB (6053.01.01) and the US Government's Office of 
Management and Budget (0925-0668). Written informed consent was obtained from participants in this study, including participants under the age of 16, which a parent and/or legal guardian approved of their participation. All methods were carried out in accordance with relevant guidelines and regulations.

\section{Consent for publication}

Not applicable.

\section{Availability of data and materials}

The datasets generated and/or analyzed during the current are available and retrieved from: https://cancercontrol.cancer.gov/brp/hbrb/flashe-study/flashe-files.

\section{Competing interests}

The authors declare that they have no competing interests.

\section{Funding}

Not applicable.

\section{Authors' contributions}

RF and GF conceptualized the study, analyzed the data. GF drafted the first version of the manuscript. RF supported the development of study from initial stage to subsequent significant revisions. CG contributed to the editing and revision of the manuscript; and all authors: read and approved the final manuscript.

\section{Acknowledgments}

The authors extend their gratitude to the participants in the FLASHE study, and to the Cornell Institute for Social and Economic Research for their support throughout the study process.

\section{References}

1. "Childhood Obesity Facts." Centers for Disease Control and Prevention, Centers for Disease Control and Prevention, 24 June 2019, .

2. Lobstein T, Jackson-Leach R, Moodie ML, Hall KD, Gortmaker SL, Swinburn BA, James WP, Wang Y, McPherson K. Child and adolescent obesity: part of a bigger picture. The Lancet. 2015 Jun 20;385(9986):2510-20.

3. Biro FM, Wien M. Childhood obesity and adult morbidities. The American journal of clinical nutrition. 2010 May 1;91(5):1499S-505S.

4. I'allemand D, Wiegand S, Reinehr T, Müller J, Wabitsch M, Widhalm K, Holl R, APV-Study Group. Cardiovascular risk in 26,008 European overweight children as established by a multicenter database. Obesity. 2008 Jul;16(7):1672-9. 
5. Rankin J, Matthews L, Cobley S, Han A, Sanders R, Wiltshire HD, Baker JS. Psychological consequences of childhood obesity: psychiatric comorbidity and prevention. Adolescent health, medicine and therapeutics. 2016;7:125.

6. Lowe CJ, Morton JB, Reichelt AC. Adolescent obesity and dietary decision making-A brain-health perspective. The Lancet Child \& Adolescent Health. 2020 May 1;4(5):388-96.

7. Suchindran C, North KE, Popkin BM, Gordon-Larsen P. Association of adolescent obesity with risk of severe obesity in adulthood. Jama. 2010 Nov 10;304(18):2042-7.

8. Chen D, Jaenicke EC, Volpe RJ. Food environments and obesity: household diet expenditure versus food deserts. American journal of public health. 2016 May;106(5):881-8.

9. Kenney EL, Gortmaker SL. United States adolescents' television, computer, videogame, smartphone, and tablet use: associations with sugary drinks, sleep, physical activity, and obesity. The Journal of pediatrics. 2017 Mar 1;182:144-9.

10. Reichert FF, Menezes AM, Wells JC, Dumith SC, Hallal PC. Physical activity as a predictor of adolescent body fatness. Sports Medicine. 2009 Apr;39(4):279-94.

11. Sallis JF, Saelens BE, Frank LD, Conway TL, Slymen DJ, Cain KL, Chapman JE, Kerr J. Neighborhood built environment and income: examining multiple health outcomes. Social science \& medicine. 2009 Apr 1;68(7):1285-93.

12. Vamosi M, Heitmann BL, Kyvik KO. The relation between an adverse psychological and social environment in childhood and the development of adult obesity: a systematic literature review. Obesity Reviews. 2010 Mar;11(3):177-84.

13. Romieu I, Dossus L, Barquera S, Blottière HM, Franks PW, Gunter M, Hwalla N, Hursting SD, Leitzmann M, Margetts B, Nishida C. Energy balance and obesity: what are the main drivers?. Cancer Causes \& Control. 2017 Mar 1;28(3):247 - 58.

14. Grusec JE, Lytton H. Socialization and the family. InSocial development 1988 (pp. 161-212). Springer, New York, NY.

15. Anderssen N, Wold B. Parental and peer influences on leisure-time physical activity in young adolescents. Research quarterly for exercise and sport. 1992 Dec 1;63(4):341-8.

16. Davison KK. Activity-related support from parents, peers, and siblings and adolescents' physical activity: are there gender differences?. Journal of Physical Activity and Health. 2004 Oct 1;1(4):36376.

17. Pate RR, Mitchell JA, Byun W, Dowda M. Sedentary behaviour in youth. British journal of sports medicine. 2011 Sep 1;45(11):906 - 13.

18. Maitland C, Stratton G, Foster S, Braham R, Rosenberg M. A place for play? The influence of the home physical environment on children's physical activity and sedentary behaviour. International Journal of Behavioral Nutrition and Physical Activity. 2013 Dec;10(1):1-21.

19. Verloigne M, Van Lippevelde W, Maes L, Brug J, De Bourdeaudhuij I. Family-and school-based correlates of energy balance-related behaviours in 10-12-year-old children: a systematic review 
within the ENERGY (EuropeaN Energy balance Research to prevent excessive weight Gain among Youth) project. Public health nutrition. 2012 Aug;15(8):1380-95.

20. Pearson N, Biddle SJ, Gorely T. Family correlates of fruit and vegetable consumption in children and adolescents: a systematic review. Public health nutrition. 2009 Feb;12(2):267-83.

21. Van der Horst K, Oenema A, Ferreira I, Wendel-Vos W, Giskes K, van Lenthe F, Brug J. A systematic review of environmental correlates of obesity-related dietary behaviors in youth. Health education research. 2007 Apr 1;22(2):203 - 26.

22. Figueroa R, Saltzman JA, Aftosmes-Tobio A, Davison KK. The Obesity Parenting Intervention Scale: Factorial Validity and Invariance Among Head Start Parents. American journal of preventive medicine. 2019 Dec 1;57(6):844-52.

23. Baranowski T, O'Connor T, Hughes S, Sleddens E, Beltran A, Frankel L, Mendoza JA,Baranowski J. Houston... We have a problem! Measurement of parenting.

24. Bourdeaudhuij ID, Oost PV. Personal and family determinants of dietary behaviour in adolescents and their parents. Psychology and health. 2000 Nov 1;15(6):751 - 70.

25. King KA, Tergerson JL, Wilson BR. Effect of social support on adolescents' perceptions of and engagement in physical activity. Journal of Physical Activity and Health. 2008 May 1;5(3):374 - 84.

26. Loth KA, MacLehose RF, Larson N, Berge JM, Neumark-Sztainer D. Food availability, modeling and restriction: How are these different aspects of the family eating environment related to adolescent dietary intake?. Appetite. 2016 Jan 1;96:80 - 6.

27. Sabiston CM, Crocker PR. Exploring self-perceptions and social influences as correlates of adolescent leisure-time physical activity. Journal of Sport and Exercise Psychology. 2008 Feb $1 ; 30(1): 3-22$.

28. Neumark-Sztainer D, Wall M, Perry C, Story M. Correlates of fruit and vegetable intake among adolescents: Findings from Project EAT. Preventive medicine. 2003 Sep 1;37(3):198-208.

29. Sallis JF, Prochaska JJ, Taylor WC, Hill JO, Geraci JC. Correlates of physical activity in a national sample of girls and boys in grades 4 through 12. Health psychology. 1999 Jul;18(4):410.

30. Vaughn AE, Tabak RG, Bryant MJ, Ward DS. Measuring parent food practices: a systematic review of existing measures and examination of instruments. International Journal of Behavioral Nutrition and Physical Activity. 2013 Dec;10(1):1-27.

31. Ridolfo $\mathrm{H}$, Maitland A. Factors that influence the accuracy of adolescent proxy reporting of parental characteristics: A research note. Journal of adolescence. 2011 Feb 1;34(1):95-103.

32. Burns RD, Pfledderer CD, Brusseau TA. Active transport, not device use, associates with self-reported school week physical activity in adolescents. Behavioral Sciences. 2019 Mar;9(3):32.

33. Oh AY, Davis T, Dwyer LA, Hennessy E, Li T, Yaroch AL, Nebeling LC. Recruitment, enrollment, and response of parent-adolescent dyads in the FLASHE study. American journal of preventive medicine. 2017 Jun 1;52(6):849 - 55. 
34. Birch LL, Fisher JO, Grimm-Thomas K, Markey CN, Sawyer R, Johnson SL. Confirmatory factor analysis of the Child Feeding Questionnaire: a measure of parental attitudes, beliefs and practices about child feeding and obesity proneness. Appetite. 2001 Jun 1;36(3):201 - 10.

35. Darling N, Cumsille P, Martínez ML. Individual differences in adolescents' beliefs about the legitimacy of parental authority and their own obligation to obey: A longitudinal investigation. Child development. 2008 Jul;79(4):1103-18.

36. Musher-Eizenman D, Holub S. Comprehensive feeding practices questionnaire: validation of a new measure of parental feeding practices. Journal of pediatric psychology. 2007 Sep 1;32(8):960 - 72.

37. Wardle J, Sanderson S, Guthrie CA, Rapoport L, Plomin R. Parental feeding style and the intergenerational transmission of obesity risk. Obesity research. 2002 Jun;10(6):453-62.

38. Davison KK, Li K, Baskin ML, Cox T, Affuso O. Measuring parental support for children's physical activity in white and African American parents: the Activity Support Scale for Multiple Groups (ACTSMG). Preventive medicine. 2011 Jan 1;52(1):39-43.

39. Larios SE, Ayala GX, Arredondo EM, Baquero B, Elder JP. Development and validation of a scale to measure Latino parenting strategies related to children's obesigenic behaviors. The parenting strategies for eating and activity scale (PEAS). Appetite. 2009 Feb 1;52(1):166 - 72.

40. "Youth Physical Activity Guidelines." Centers for Disease Control and Prevention, Centers for Disease Control and Prevention, 29 May 2019,

Physical\%20Activity\%20Guidelines\%20for,to\%2Dvigorous\%20physical\%20activity\%20daily.

41. Bland JM, Altman DG. Statistics notes: Cronbach's alpha. Bmj. 1997 Feb 22;314(7080):572.

42. Hu LT, Bentler PM. Cutoff criteria for fit indexes in covariance structure analysis: Conventional criteria versus new alternatives. Structural equation modeling: a multidisciplinary journal. 1999 Jan $1 ; 6(1): 1-55$.

43. Sleddens EF, Kremers SP, Hughes SO, Cross MB, Thijs C, De Vries NK, O'Connor TM. Physical activity parenting: a systematic review of questionnaires and their associations with child activity levels. Obesity reviews. 2012 Nov;13(11):1015-33.

44. Davison KK, Mâsse LC, Timperio A, Frenn MD, Saunders J, Mendoza JA, Gobbi E, Hanson P, Trost SG. Physical activity parenting measurement and research: challenges, explanations, and solutions. Childhood Obesity. 2013 Aug 1;9(s1):S-103.

45. Ensminger ME, Forrest CB, Riley AW, Kang M, Green BF, Starfield B, Ryan SA. The validity of measures of socioeconomic status of adolescents. Journal of Adolescent Research. 2000 May;15(3):392-419.

46. Kerckhoff AC, Mason WM, Poss SS. On the accuracy of children's reports of family social status. Sociology of Education. 1973 Apr 1:219-47.

47. Taylor A, Wilson C, Slater A, Mohr P. Parent-and child-reported parenting. Associations with child weight-related outcomes. Appetite. $2011 \mathrm{Dec}$ 1;57(3):700-6.

48. Zhang Y, Davey C, Larson N, Reicks M. Influence of parenting styles in the context of adolescents' energy balance-related behaviors: Findings from the FLASHE study. Appetite. 2019 Nov $1 ; 142: 104364$. 
49. Adams SA, Matthews CE, Ebbeling CB, Moore CG, Cunningham JE, Fulton J, Hebert JR. The effect of social desirability and social approval on self-reports of physical activity. American journal of epidemiology. 2005 Feb 15;161(4):389-98.

50. Hebert JR, Clemow L, Pbert L, Ockene IS, Ockene JK. Social desirability bias in dietary self-report may compromise the validity of dietary intake measures. International journal of epidemiology. $1995 \mathrm{Apr}$ 1;24(2):389 - 98 .

51. Nusser SM, Beyler NK, Welk GJ, Carriquiry AL, Fuller WA, King BM. Modeling errors in physical activity recall data. Journal of Physical Activity and Health. 2012 Jan 1;9(s1):S56-67.

52. Shennar-Golan $\mathrm{V}$, Walter $\mathrm{O}$. Physical activity intensity among adolescents and association with parent-adolescent relationship and well-being. American journal of men's health. 2018 Sep;12(5):1530-40.

53. Solomon-Moore E, Toumpakari Z, Sebire SJ, Thompson JL, Lawlor DA, Jago R. Roles of mothers and fathers in supporting child physical activity: a cross-sectional mixed-methods study. BMJ open. 2018 Jan 1;8(1):e019732. 